\title{
Serum Calcium and Incident Diabetes: An Observational Study and Meta-Analysis
}

Running title: Calcium and diabetes

Chor-Wing Sing ${ }^{1}$, Vincent KF Cheng ${ }^{2}$, Daniel KC Ho ${ }^{1}$, Annie WC Kung ${ }^{2}$, Bernard MY Cheung $^{2,3,4}$, Ian CK Wong ${ }^{1,4,5}$, Kathryn CB Tan ${ }^{2,3}$, Jordi Salas-Salvadó ${ }^{6,7}$, Nerea BecerraTomas $^{6,7}$, Ching-Lung Cheung ${ }^{1,2,3,4}$

${ }^{1}$ Department of Pharmacology and Pharmacy, Li Ka Shing Faculty of Medicine, The University of Hong Kong, Hong Kong ${ }^{2}$ Department of Medicine, Li Ka Shing Faculty of Medicine, The University of Hong Kong, Hong Kong ${ }^{3}$ Research Centre of Heart, Brain, Hormone \& Healthy Aging, Li Ka Shing Faculty of Medicine, The University of Hong Kong, Hong Kong ${ }^{4}$ The State Key Laboratory of Pharmaceutical Biotechnology, Li Ka Shing Faculty of Medicine, The University of Hong Kong, Hong Kong ${ }^{5}$ Centre for Paediatric Pharmacy Research, Research Department of Practice and Policy, School of Pharmacy, University College London, London, United Kingdom ${ }^{6}$ Human Nutrition Unit, Faculty of Medicine and Health Sciences, Institut d'Investigacio Sanitaria Pere Virgili, Universitat Rovira i Virgili, Reus, Spain ${ }^{7}$ Centro de Investigación Biomédica en Red Fisiopatología de la Obesidad y Nutrición (CIBEROBN), Institute of Health Carlos III, Madrid, Spain

\section{Correspondence and reprint requests:}

Ching-Lung Cheung, $\mathrm{PhD}$

Email: lung1212@hku.hk

Tel: +852-2831-5085 Fax: +852-2816-2095 
Word counts: 209 (Abstract); 3352 (main text)

Keywords: Diabetes; calcium; bone metabolism; mineral metabolism; meta-analysis

Acknowledgments: Funding - This study is supported by Research Grants Council, University Grants Committee, Hong Kong [grant number HKU17104314]; the Health and Medical Research Fund, HKSAR [grant number HKU12132451].

Conflict of Interest: Chor-Wing Sing, Vincent KF Cheng, Daniel KC Ho, Annie WC Kung, Bernard MY Cheung, Ian CK Wong, Kathryn CB Tan, Jordi Salas-Salvadó, Nerea Becerra-Tomas, Ching-Lung Cheung declare that they have no conflict of interest.

\title{
Mini-abstract:
}

The study aimed to prospectively evaluate if serum calcium is related to diabetes incidence in Hong Kong Chinese. The results showed that serum calcium has a significant association with increased risk of diabetes. The result of meta-analysis reinforced our findings.

\begin{abstract}
Purpose This study aimed to evaluate the association of serum calcium, including serum total calcium and albumin-corrected calcium, with incident diabetes in Hong Kong Chinese.

Methods We conducted a retrospective cohort study in 6096 participants aged 20 or above and free of diabetes at baseline. Serum calcium was measured at baseline. Incident diabetes was determined from several electronic databases. We also searched relevant databases for studies on serum calcium and incident diabetes and conducted a meta-analysis using fixedeffect modelling.
\end{abstract}


Results During 59130.9 person-years of follow-up, 631 participants developed diabetes. Serum total calcium and albumin-corrected calcium were associated with incident diabetes in the unadjusted model. After adjusting for demographic and clinical variables, the association remained significant only for serum total calcium (HR 1.32, 95\%CI 1.02-1.70, highest vs. lowest quartile). In a meta-analysis of four studies including the current study, both serum total calcium (pooled RR 1.38; 95\%CI 1.15-1.65; $\mathrm{I}^{2}=5 \%$, comparing extreme quantiles) and albumin-corrected calcium (pooled RR 1.29; 95\%CI 1.03-1.61; $\mathrm{I}^{2}=0 \%$, comparing extreme quantiles) were associated with incident diabetes. Penalized regression splines showed that the association of incident diabetes with serum total calcium and albumin-correlated calcium was non-linear and linear, respectively.

Conclusions Elevated serum calcium concentration is associated with incident diabetes. The mechanism underlying this association warrants further investigation. 


\section{Introduction}

Calcium is a vital component in bone metabolism and is essential for other important biological functions including nerve impulse transmission, blood clotting, cell signaling, and muscle contraction [1]. Calcium homeostasis is tightly controlled by calcitonin, parathyroid hormone $(\mathrm{PTH})$, and calcitriol [1]. Elevated serum calcium concentration has been demonstrated to be associated with a wide range of health outcomes including cardiovascular morbidity and mortality [2,3], and metabolic syndrome [4].

Growing evidence suggests that calcium homeostasis may be linked to glucose metabolism and development of diabetes. Calcium-sensing receptor $(\mathrm{CaR})$ is expressed not only in tissues involved in calcium homeostasis (e.g. parathyroid gland), but also in other tissues, such as pancreatic islets of Langerhans [5]. An in vitro study showed that activation of CaR in pancreatic beta-cells initiated an insulin secretory response [6], and is involved in intraislet communication between beta-cells [5]. Some [7-9] but not all [10] previous observational studies showed that serum calcium concentrations were positively associated with impairment of glucose tolerance, insulin resistance and insulin secretion, suggesting that more studies are warranted to investigate the association between serum calcium and diabetes development.

Recent studies show that serum calcium is associated with an increased risk of diabetes in Caucasian populations [10-12]. Since there are ethnic differences in bone and mineral 
metabolism [13-15], whether serum calcium concentration is also associated with the risk of diabetes in Chinese populations remains unknown. In the present study, we aimed to evaluate the relationship between serum calcium and the risk of incident diabetes in a retrospective Chinese cohort, and to study further the relationship between serum calcium and the risk of diabetes in a meta-analysis of observational studies.

\section{Materials and Methods}

\section{Study participants}

The study participants were drawn from the Hong Kong Osteoporosis Study (HKOS), which was conducted at the University of Hong Kong Osteoporosis Centre at Queen Mary Hospital to determine the genetic and environmental risk factors for osteoporosis and related traits. The participants were community-dwelling Southern Chinese men and women recruited between 1995 and 2010 during public road shows and health fairs on osteoporosis held in various districts of Hong Kong. Details have been described previously [16-18]. Baseline demographic data on anthropometric measurements, socioeconomic status, education level, and medical and reproductive history were obtained using a structured questionnaire administered by a trained research assistant. Additionally, information on lifestyle, smoking, alcohol consumption, and physical activity, were also recorded. All participants gave informed consent and the study was conducted according to the Declaration of Helsinki. The study protocol was approved by the Institutional Review 
Board of the University of Hong Kong and the Hospital Authority Hong Kong West Cluster Hospitals.

To ascertain the clinical outcomes, the osteoporosis database was linked to the electronic medical record (EMR) of the Hong Kong Hospital Authority, a publicly funded primary, secondary, and tertiary healthcare provider that consists of 37 hospitals and account for $>90 \%$ of the medical care provided in Hong Kong [19]. Among 9,202 participants aged $\geq 20$ in the study, 1,018 who had diabetes at baseline were excluded for the present study. In addition, 173 participants with chronic kidney disease (CKD, defined as eGFR <60 $\mathrm{mL} / \mathrm{min} / 1.73 \mathrm{~m}^{2}$ ) that affects bone and mineral metabolism were also excluded. Participants with any missing variable in the multivariable model $(n=1,793)$ or on osteoporosis medication $(n=122)$ were also excluded. A total of 6,096 participants were included in the final analysis (eligibility flow of study is shown in Supplementary Figure 1).

\section{Ascertainment of diabetes}

Incident diabetes was ascertained from the EMR in several ways: (1) having a diagnosis of diabetes (ICD-9 code 250); (2) having a prescription record of diabetic medications; (3) having a laboratory record of $\mathrm{A} 1 \mathrm{C} \geq 47.5 \mathrm{mmol} / \mathrm{mol}(\geq 6.5 \%)$ or fasting plasma glucose concentration $>7.0 \mathrm{mmol} / \mathrm{l}$; (4) having enrolled in a diabetic complication screening program. Length of follow-up for each participant was calculated as the time from the baseline examination date to the date of first diabetes ascertainment, date of death, or May 
1, 2014, whichever was earliest. To validate the diabetes ascertainment, we conducted a phone interview in $10 \%$ of participants $(n=610)$ by a trained research assistant. Kappa statistics (prevalence-adjusted and bias-adjusted kappa $=0.881$ ) showed that self-reported diabetes and diabetes ascertainment from EMR were in excellent agreement.

\section{Assessment of serum calcium and other covariates}

Serum calcium, phosphate, albumin, and alkaline phosphatase (ALP) were measured with a Hitachi 747 random access analyzer (Roche Molecular Biochemicals, Mannheim, Germany). Albumin-corrected calcium was calculated using the formula commonly used in clinical practice: corrected calcium $(\mathrm{mmol} / \mathrm{L})=$ serum total calcium $+0.02 *(40-$ serum albumin $(\mathrm{g} / \mathrm{L}))$ [20]. Serum PTH was measured by two-site sandwich chemiluminometric assay with a mouse monoclonal anti-human PTH antibody measuring intact PTH (Chiron Diagnostic Corporation, East Walpole, Mass., USA) with intraassay and interassay coefficients of variation of 5.6 and $6.6 \%$, respectively [18]. Baseline bone mineral density (BMD) at the femoral neck was measured using a dual-energy X-ray absorptiometry machine (Hologic QDR 4500, Waltham, MA, USA). BMD T-scores were determined according to the local Southern Chinese norm. The in vivo precision for hip BMD measurement was $1.5 \%$. Although BMD data at other skeletal sites (such as lumbar spine) were also available, we studied BMD at the femoral neck because it was more clinically relevant for diagnosing osteoporosis and determining fracture risk. 
Age, sex, smoking status, drinking status, and physical activity were self-reported at baseline. Physical activity was defined as having $\geq 1$ hour of exercise per week [16]. Body mass index (BMI) was calculated from height $(\mathrm{m})$ and weight $(\mathrm{kg})$ measured during baseline examination using a standardized protocol. Since serum vitamin D was not measured, season was used as a surrogate to reflect the effect of vitamin D on serum calcium. Season was defined as the month in which baseline markers were measured. We grouped measurement in summer and autumn (from May to October) as one group and measurement in winter and spring (from November to April) as another group [21].

\section{Meta-analysis}

Systematic search in PubMed, Medline and Cochrane library (2 ${ }^{\text {nd }}$ July 2015) was performed by 2 independent reviewers (K.F.C. and K.C.H.) using search terms ("Serum calcium" AND "diabetes", "total serum calcium" AND "diabetes", "corrected calcium" AND diabetes). Potential eligible articles were first identified by screening titles and abstracts, and then full articles selected were read and evaluated. Studies were included if they reported serum calcium level or albumin-corrected calcium with incident diabetes data, the result should include odds ratio (OR) or hazard ratio (HR). We employed the Newcastle-Ottawa Scale [22] (9-star based system) to assess the quality of the selected studies, the assessment covers the selection of study groups, comparability of study groups, outcomes assessment and follow-up. Studies with 9-7, 6-4 and 3-0 score would be considered as high, moderate, and low quality respectively. 
We used risk ratio (RR) as the common measure across studies. HR was considered as broadly equivalent to RR. We transformed OR reported in the studies to RR using the formula $\mathrm{RR}=\mathrm{OR} /\left[\left(1-\mathrm{P}_{0}\right)+\left(\mathrm{P}_{0} \times \mathrm{OR}\right)\right]$ where $\mathrm{P}_{0}$ stands for the prevalence of diabetes in US in 2014 (9.3\%, http://www.diabetes.org/diabetes-basics/statistics/). Heterogeneity across studies was assessed; it was considered insignificant if $\mathrm{P}>0.10$ and $\mathrm{I}^{2} \leq 50 \%$. The pooled RR was calculated using a fixed model with inverse variance. Review Manager 5.3 (tech.cochrane.org/revman) was the program used for meta-analysis.

\section{Statistical methods}

Baseline participant's characteristics with and without incident diabetes were compared using the Student $\mathrm{t}$ test for continuous data and the $\chi 2$ test for categorical data. Pearson correlation coefficients were calculated to assess the relationship between serum total calcium and other variables. Time-to-event analyses were performed and HR and the 95\% confidence interval (CI) were calculated using Cox proportional hazard models. Survival time was calculated from the baseline date to the date of diabetes diagnosis, death, or end of study (1 May 2014). In the Cox-regression model, model 1 was adjusted for age and sex; model 2 was further adjusted for BMI, smoking status, drinking status, and physical activity; and model 3 was the full adjusted model with further adjustment for serum albumin, phosphate, PTH, ALP, femoral neck BMD T-score, and season. For albumin-corrected calcium, although serum albumin was used in the calculation of albumin-corrected calcium 
level, the correlation between these two variables was modest $(-0.253, \mathrm{p}<0.01$, data not shown), suggesting that multicollinearity should be minimal. Therefore, we adjusted for albumin in model 3. The proportional hazards assumption was evaluated for the variables in the final multivariable mortality model using the Schoenfeld residuals method. The proportional assumption was not violated in the model. Serum calcium was further modeled as quartiles, and the lowest quartile was used as reference. To compare the relative strength of association of each variable with incident diabetes, we calculated HRs per 1-SD increment from the mean of the continuous variables (standard coefficients). Penalized regression spline was used to gain additional insight into the potential nonlinearity of the effect of serum calcium using the R packages "pspline" and "survival". To plot the penalized regression spline, outliers of serum calcium were removed using the Median Absolute Deviation (MAD) method. The outlier was defined as value smaller than median$3 *$ MAD or larger than median $+3 *$ MAD. In addition, as sensitivity analysis we examined the differences of association across predefined subgroups, including sex, age, BMI, smoking status, drinking status, and physical activity, using the interaction test. All statistical analyses were performed using SPSS version 18.0 software (SPSS Inc, Chicago, IL) or R version 3.0.1 (www.R-project.org).

\section{Results}

\section{Baseline characteristics}


The flow diagram for the study is provided in Supplementary figure 1. For the 6,096 participants included in our analysis, the mean age at diagnosis of diabetes was 52.5 years (range 20 to 96). Baseline characteristics of the 6,096 participants included in the study, stratified according to incident diabetes status, are presented in Table 1. Participants with incident diabetes were older, with significantly higher BMI, ALP, calcium, and physical activity, and significantly lower BMD and PTH concentrations. Serum total calcium was positively correlated with BMI, physical activity, serum albumin, serum ALP, serum phosphate, and season; whereas it was inversely correlated with BMD and serum PTH.

\section{Serum calcium and incident diabetes}

A total of 631 cases of incident diabetes were observed over a median follow-up of 10.2 years, with a maximum follow-up of 19.1 years (total follow-up: 59,130.9 person-years; 10.7 incident diabetes per 1,000 person-years). Serum total calcium and albumin-corrected calcium were significantly associated with incident diabetes in the crude model (Table 2). After further adjustment for age, sex, lifestyle and other bone and mineral metabolism markers (Model 3), the association between diabetes incidence and serum total calcium (HR 1.11 per 1-SD increment, 95\%CI 1.02-1.21) and albumin-corrected calcium (HR 1.10 per 1-SD increment, 95\%CI 1.02-1.20) remained statistically significant.

When serum total calcium and corrected calcium were analyzed as quartiles, the third and highest quartiles of both variables were significantly associated with incident diabetes in 
the crude model when comparing with the lowest quartile $\left(\mathrm{P}_{\text {trend }}<0.001\right.$, Table 3). After further adjustment for age, sex, lifestyle, and other bone and mineral metabolism markers (models 1 to 3 ), the association of serum total calcium with incident diabetes remained statistically significant, whereas the association of albumin-corrected calcium became insignificant, although the trend across the quartiles was significant $\left(\mathrm{P}_{\text {trend }}=0.046\right)$. In the fully adjusted model, participants in the third quartile (HR, 1.37; 95\% CI, 1.07 to 1.74$)$ and the highest quartile (HR, 1.32; 95\% CI, 1.02 to 1.70$)$ of serum total calcium had significantly elevated risks for diabetes when compared with participants in the lowest quartile. Penalized regression spline for the association of serum calcium and risk of diabetes showed that serum total calcium and albumin-correlated calcium had a non-linear and linear relationship with incident diabetes, respectively (Supplementary figure 2). The associations across the subgroups did not show significant differences (all $\mathrm{p}$ for interaction $>0.05$; Supplementary figure 3 ).

To assess potential bias due to undiagnosed diabetes at baseline, we performed a sensitivity analyses for serum total calcium, which excluded participants with incident diabetes in the first 3-years or the first 5-years of follow up. Slightly increased HRs were observed with significant trend across quartiles $\left(\mathrm{P}_{\text {trend }}=0.039\right.$ when we exclude cases in the first 3 -years; $\mathrm{P}_{\text {trend }}=0.031$, when we exclude cases in the first 5-years; Supplementary Table 1).

\section{Meta-analyses of observational studies on serum calcium and incident diabetes}


We performed a meta-analysis of observational studies to summarize the existing evidence of the association between serum total calcium and albumin-corrected calcium with the risk of diabetes. The screening process is shown in Supplementary Figure 4. Three studies [1012] together with our current study were selected. Additional data were obtained from the authors of the two studies $[10,12]$. The characteristics of the studies are summarized in Supplementary Table 2. The risk estimates comparing extreme quantiles, except the Insulin Resistance Atherosclerosis Study (IRAS) which used the second quintile as a reference group, were pooled for analysis. Figure 1a) shows a forest plot of the association between serum total calcium level and diabetes risk, whereas Figure 1b) shows the association between corrected calcium and diabetes risk. No statistically significant heterogeneity was

found across studies (serum total calcium, $\mathrm{P}_{\text {heterogeneity }}=0.35, \mathrm{I}^{2}=5 \%$; albumin-corrected calcium, $\mathrm{P}_{\text {heterogeneity }}=0.45, \mathrm{I}^{2}=0 \%$ ). The fixed effect model suggested an increased risk of diabetes in individuals with elevated serum total calcium level (pooled RR, 1.38; 95\% CI: 1.15 to $\left.1.65 ; \mathrm{P}_{\text {meta }}=0.001\right)$ and albumin-corrected calcium level (pooled RR, $1.29 ; 95 \% \mathrm{CI}$ : 1.03 to $\left.1.61 ; \mathrm{P}_{\text {meta }}=0.02\right)$. Similar results were observed even in random effects model (data not shown).

\section{Discussion}

In this study we observed that serum total calcium was associated with incident diabetes, and this finding was further confirmed in the meta-analysis. The association was 
independent of several established risk factors of diabetes, suggesting that serum calcium is independently related to the risk of diabetes.

Our study showed a positive, non-linear association between serum total calcium and incident diabetes. Participants with a total calcium $>2.44 \mathrm{mmol} / \mathrm{l}$ had a $32 \%$ increased risk of diabetes compared to the reference group. The findings are consistent with the results of two studies included in the meta-analysis. In the Tromso Study [11], participants with the highest category of serum total calcium $(2.50-2.60 \mathrm{mmol} / \mathrm{L})$ had significant increased risk of incident diabetes (HR 1.36, 95\% CI 1.04-1.77) when compared to those in the lowest category $(2.20-2.29 \mathrm{mmol} / \mathrm{L})$. The IRAS study reported a non-linear association between calcium and incident diabetes [10]. Our result, by pooling the data from Tromso and IRAS studies together with our current study in a meta-analysis, provided further evidence to support the association.

Unlike serum total calcium, we observed a positive linear association between albumincorrected calcium and diabetes risk, which is consistent with the finding reported in the IRAS study [10]. However, when albumin-correlated calcium was analyzed in quartiles in the HKOS, the association was non-significant. This finding is in agreement with the Prevención con Dieta Mediterránea (PREDIMED) study [11] and the IRAS study [10]. The insignificant association in each individual study could be due to the small sample size in 
each study, resulting in insufficient power to detect the association. Nevertheless, our metaanalysis showed that serum calcium is associated with incident diabetes.

The role of serum calcium in diabetes development is unclear but emerging evidence indicated that calcium may affect glucose metabolism. Calcium ions are involved in the regulation of insulin secretion and action at cellular level [23], potentially through the activation of CaR [5,6]. Recent studies showed a potential interaction between calcium and adiponectin. Adiponectin has three calcium-binding sites and the formation of trimeric adiponectin can be triggered by calcium [24]. Interestingly, a significant interaction between total serum calcium and adiponectin levels on all-cause mortality in end-stage renal disease (ESRD) people has been reported. Adiponectin was significantly associated with all-cause mortality in ESRD people with high serum total calcium (defined as $>2.33$ $\mathrm{mmol} / \mathrm{l}$ ) levels only [25], which is equivalent to the second to fourth quartile in the current study. Given that patients with ESRD are different from the general population, further studies investigating the associations between serum calcium in the general population with metabolic risk factors are warranted.

In the IRAS study, a significant association between serum phosphate concentrations and risk of diabetes was reported. However, we did not found any significant association between these two variables in the current study even when using the same cutoff (Supplementary Table 3). Difference in findings could be due to ethnic differences in 
phosphate metabolism [26]. A study by Yan et al. showed that Chinese subjects had a more rapid renal clearance of phosphate compared to the British and Gambian, resulting in little change in the phosphate level after oral phosphate administration [27]. With a stable phosphate level, the effect of phosphate on the development of diabetes may be minimal.

PTH and vitamin D regulate calcium homeostasis and are important bone markers. Therefore, the effects of PTH and vitamin D on the association of serum calcium with incident diabetes are worth investigating. The current study showed no significant association between serum PTH and incident diabetes in any models (data not shown), suggesting that serum PTH has no effect on incident diabetes, and the effect of calcium on incident diabetes is independent of PTH regulation. A previous study showed that the association between PTH and glycemic traits was confounded by serum calcium levels [7], further highlighting the role of serum calcium in glycemic traits. Unfortunately, vitamin D levels were not available in the current study. Several observational studies, including a meta-analysis, reported that low peripheral levels of vitamin D appeared to be associated with an increased risk of diabetes [28-30]. However, randomized clinical trials did not report consistent findings. In the Women's Health Initiative trial, no reduction in the risk of diabetes was found in 2,291 postmenopausal women treated with 400 IU/day of vitamin D3 supplement plus $1,000 \mathrm{mg} /$ day of calcium. The absence of association may be explained by the low dose of vitamin D3 and suboptimal supplement adherence $(<60 \%)$ [31]. Results from other trials were not conclusive due to small sample size, large heterogeneity in study 
design, and different techniques to measure vitamin D concentrations. Therefore, a large trial with well-defined assessment is warranted to investigate the association between vitamin $\mathrm{D}$, calcium and diabetes.

Our study has several strengths. The study population is large. The long follow-up and large number of incident cases of diabetes provided ample statistical power. Factors affecting bone and mineral metabolism were collected at baseline and were excluded in the current study. Sensitivity analysis excluded incident diabetes in the first 3 or 5 years to avoid bias. Nevertheless, there are limitations. First, plasma glucose measurements were not available on all participants. Glycemic measurements are known to be strong predictors of diabetes, and whether the association was confounded by glycemic measurements are unknown. However, based on the previous study of serum calcium in incident diabetes [10], in which the association between serum calcium and incident diabetes was not confounded by fasting and 2-hour glucose concentrations, insulin sensitivity index, or acute insulin response, we believe that our findings (on serum calcium at least) are also unlikely to be confounded by glycemic measurements. Second, observational data cannot infer causality. Third, incident diabetes was ascertained from electronic medical records, which means that undiagnosed diabetes could be a limitation. However, the incidence of diabetes in the current study (10.7 incident diabetes per 1,000 person-years) is comparable to the figures reported in the literature (9.1-9.5 incident diabetes per 1,000 person-years) [32,33], suggesting that the problem associated with undiagnosed diabetes should be minimal. 
Fourth, calcium intake from diet and several important markers of bone and mineral metabolism such as vitamin D, parathyroid hormone related protein, and FGF23 were not included in the study. Whether the observed associations were confounded by these factors remains unknown. Lastly, we do not have the data of blood pressure and lipid profiles, which are known risk factors for diabetes. However, in the TROMSO study, there was adjustment for these two risk factors and the association remained significant, although the HR was slightly decreased.

In conclusion, our study showed that elevated serum calcium concentration, including both total calcium and albumin-corrected calcium, was associated with an increased risk of diabetes in a Chinese population. Investigation on the role of calcium in the development of diabetes is warranted.

\section{References}

1. Peacock M (2010) Calcium metabolism in health and disease. Clin J Am Soc Nephrol 5 Suppl 1:S23-30. doi:10.2215/CJN.05910809

2. Foley RN, Collins AJ, Ishani A, Kalra PA (2008) Calcium-phosphate levels and cardiovascular disease in community-dwelling adults: the Atherosclerosis Risk in Communities (ARIC) Study. Am Heart J 156 (3):556-563. doi:10.1016/j.ahj.2008.05.016

3. Larsson TE, Olauson H, Hagstrom E, Ingelsson E, Arnlov J, Lind L, Sundstrom J (2010) Conjoint effects of serum calcium and phosphate on risk of total, cardiovascular, and noncardiovascular mortality in the community. Arterioscler Thromb Vasc Biol 30 (2):333-339. doi:10.1161/ATVBAHA.109.196675

4. Kim MK, Kim G, Jang EH, Kwon HS, Baek KH, Oh KW, Lee JH, Yoon KH, Lee WC, Lee KW, Son HY, Kang MI (2010) Altered calcium homeostasis is correlated with the presence of metabolic syndrome and diabetes in middle-aged and elderly Korean subjects: the Chungju Metabolic Disease $\begin{array}{llllll}\text { Cohort study } & \text { (CMC study). } & \text { Atherosclerosis } 212 & \text { (2):674-681. }\end{array}$ doi:10.1016/j.atherosclerosis.2010.07.005 
5. Gray E, Muller D, Squires PE, Asare-Anane H, Huang GC, Amiel S, Persaud SJ, Jones PM (2006) Activation of the extracellular calcium-sensing receptor initiates insulin secretion from human islets of Langerhans: involvement of protein kinases. J Endocrinol 190 (3):703-710. doi:190/3/703 [pii]

10.1677/joe.1.06891

6. Jones PM, Kitsou-Mylona I, Gray E, Squires PE, Persaud SJ (2007) Expression and function of the extracellular calcium-sensing receptor in pancreatic beta-cells. Arch Physiol Biochem 113 (3):98-103. doi:781803965 [pii]

\section{$10.1080 / 13813450701531185$}

7. Yamaguchi T, Kanazawa I, Takaoka S, Sugimoto T (2011) Serum calcium is positively correlated with fasting plasma glucose and insulin resistance, independent of parathyroid hormone, in male patients with type 2 diabetes mellitus. Metabolism 60 (9):1334-1339. doi:10.1016/j.metabol.2011.02.003

8. Sun G, Vasdev S, Martin GR, Gadag V, Zhang H (2005) Altered calcium homeostasis is correlated with abnormalities of fasting serum glucose, insulin resistance, and beta-cell function in the Newfoundland population. Diabetes 54 (11):3336-3339

9. Hagstrom E, Hellman P, Lundgren E, Lind L, Arnlov J (2007) Serum calcium is independently associated with insulin sensitivity measured with euglycaemic-hyperinsulinaemic clamp in a community-based cohort. Diabetologia 50 (2):317-324. doi:10.1007/s00125-006-0532-9

10. Lorenzo C, Hanley AJ, Rewers MJ, Haffner SM (2014) Calcium and phosphate concentrations and future development of type 2 diabetes: the Insulin Resistance Atherosclerosis Study. Diabetologia. doi:10.1007/s00125-014-3241-9

11. Jorde R, Schirmer H, Njolstad I, Lochen ML, Bogeberg Mathiesen E, Kamycheva E, Figenschau Y, Grimnes G (2013) Serum calcium and the calcium-sensing receptor polymorphism rs17251221 in relation to coronary heart disease, type 2 diabetes, cancer and mortality: the Tromso Study. Eur J Epidemiol 28 (7):569-578. doi:10.1007/s10654-013-9822-y

12. Becerra-Tomas N, Estruch R, Bullo M, Casas R, Diaz-Lopez A, Basora J, Fito M, Serra-Majem L, Salas-Salvado J (2014) Increased Serum Calcium Levels and Risk of Type 2 Diabetes in Individuals at High Cardiovascular Risk. Diabetes care. doi:dc14-0898 [pii]

10.2337/dc14-0898

13. Bryant RJ, Wastney ME, Martin BR, Wood O, McCabe GP, Morshidi M, Smith DL, Peacock M, Weaver CM (2003) Racial differences in bone turnover and calcium metabolism in adolescent females. J Clin Endocrinol Metab 88 (3):1043-1047. doi:10.1210/jc.2002-021367

14. Gutierrez OM (2011) Recent insights into racial differences in bone and mineral metabolism. Current opinion in endocrinology, diabetes, and obesity 18 (6):347-351. doi:10.1097/MED.0b013e32834b4c5e

15. Wu L, Martin BR, Braun MM, Wastney ME, McCabe GP, McCabe LD, DiMeglio LA, Peacock M, Weaver CM (2010) Calcium requirements and metabolism in Chinese-American boys and girls. Journal of bone and mineral research : the official journal of the American Society for Bone and Mineral Research 25 (8):1842-1849. doi:10.1002/jbmr.76

16. Cheung CL, Tan KC, Bow CH, Soong CS, Loong CH, Kung AW (2012) Low handgrip strength is a predictor of osteoporotic fractures: cross-sectional and prospective evidence from the Hong Kong Osteoporosis Study. Age (Dordr) 34 (5):1239-1248. doi:10.1007/s11357-011-9297-2

17. Lau HH, Ng MY, Ho AY, Luk KD, Kung AW (2005) Genetic and environmental determinants of bone mineral density in Chinese women. Bone 36 (4):700-709. doi:S8756-3282(05)00024-4 [pii]

10.1016/j.bone.2005.01.014 
18. Mei J, Yeung SS, Kung AW (2001) High dietary phytoestrogen intake is associated with higher bone mineral density in postmenopausal but not premenopausal women. J Clin Endocrinol Metab 86 (11):5217-5221. doi:10.1210/jcem.86.11.8040

19. Mok CC, Kwok CL, Ho LY, Chan PT, Yip SF (2011) Life expectancy, standardized mortality ratios, and causes of death in six rheumatic diseases in Hong Kong, China. Arthritis Rheum 63 (5):1182-1189. doi:10.1002/art.30277

20. Bushinsky DA, Monk RD (1998) Electrolyte quintet: Calcium. Lancet 352 (9124):306-311

21. Cheung CL, Lau KS, Sham PC, Tan KC, Kung AW (2013) Genetic variant in vitamin D binding protein is associated with serum 25-hydroxyvitamin D and vitamin D insufficiency in southern Chinese. J Hum Genet 58 (11):749-751. doi:10.1038/jhg.2013.84

22. Stang A (2010) Critical evaluation of the Newcastle-Ottawa scale for the assessment of the quality of nonrandomized studies in meta-analyses. European journal of epidemiology 25 (9):603605. doi:10.1007/s10654-010-9491-z

23. Pittas AG, Lau J, Hu FB, Dawson-Hughes B (2007) The role of vitamin D and calcium in type 2 diabetes. A systematic review and meta-analysis. J Clin Endocrinol Metab 92 (6):2017-2029. doi:jc.2007-0298 [pii]

10.1210/jc.2007-0298

24. Yu D, Zhang C, Wang H, Qin P (2013) Characterization of the weak calcium binding of trimeric globular adiponectin. Cell Biochem Funct 31 (4):338-343. doi:10.1002/cbf.2906

25. Markaki A, Kyriazis J, Stylianou K, Fragkiadakis GA, Perakis K, Margioris AN, Ganotakis ES, Daphnis E (2012) The role of serum magnesium and calcium on the association between adiponectin levels and all-cause mortality in end-stage renal disease patients. PLoS One 7 (12):e52350. doi:10.1371/journal.pone.0052350

PONE-D-12-22616 [pii]

26. Redmond J, Jarjou LM, Zhou B, Prentice A, Schoenmakers I (2014) Ethnic differences in calcium, phosphate and bone metabolism. The Proceedings of the Nutrition Society 73 (2):340-351. doi:10.1017/S0029665114000068

27. Yan L, Schoenmakers I, Zhou B, Jarjou LM, Smith E, Nigdikar S, Goldberg GR, Prentice A (2009) Ethnic differences in parathyroid hormone secretion and mineral metabolism in response to oral phosphate administration. Bone 45 (2):238-245. doi:10.1016/j.bone.2009.04.237

28. Pittas AG, Dawson-Hughes B, Li T, Van Dam RM, Willett WC, Manson JE, Hu FB (2006) Vitamin D and calcium intake in relation to type 2 diabetes in women. Diabetes care 29 (3):650-656 29. Knekt P, Laaksonen M, Mattila C, Harkanen T, Marniemi J, Heliovaara M, Rissanen H, Montonen J, Reunanen A (2008) Serum vitamin D and subsequent occurrence of type 2 diabetes. Epidemiology 19 (5):666-671. doi:10.1097/EDE.0b013e318176b8ad

30. Song Y, Wang L, Pittas AG, Del Gobbo LC, Zhang C, Manson JE, Hu FB (2013) Blood 25hydroxy vitamin $\mathrm{D}$ levels and incident type 2 diabetes: a meta-analysis of prospective studies. Diabetes care 36 (5):1422-1428. doi:10.2337/dc12-0962

31. de Boer IH, Tinker LF, Connelly S, Curb JD, Howard BV, Kestenbaum B, Larson JC, Manson JE, Margolis KL, Siscovick DS, Weiss NS (2008) Calcium plus vitamin D supplementation and the risk of incident diabetes in the Women's Health Initiative. Diabetes care 31 (4):701-707. doi: $10.2337 / \mathrm{dc} 07-1829$

32. Odegaard AO, Koh WP, Butler LM, Duval S, Gross MD, Yu MC, Yuan JM, Pereira MA (2011) Dietary patterns and incident type 2 diabetes in chinese men and women: the singapore chinese health study. Diabetes care 34 (4):880-885. doi:10.2337/dc10-2350 
33. Fan S, Chen J, Huang J, Li Y, Zhao L, Liu X, Li J, Cao J, Yu L, Deng Y, Chen N, Guo D, Gu D (2015) Physical activity level and incident type 2 diabetes among Chinese adults. Medicine and science in sports and exercise 47 (4):751-756. doi:10.1249/MSS.0000000000000471 
Table 1. Baseline characteristics of the participants stratified by incident diabetes status.

\begin{tabular}{|c|c|c|c|c|}
\hline Characteristics & $\begin{array}{l}\text { Without incident } \\
\text { diabetes }(n=5,465)\end{array}$ & $\begin{array}{c}\text { With incident } \\
\text { diabetes }(n=631)\end{array}$ & P-value & $\begin{array}{c}\text { Correlation } \\
\text { with serum } \\
\text { total calcium^^}\end{array}$ \\
\hline Female & $3,952 \quad(72.3)$ & $442 \quad(70)$ & 0.23 & - \\
\hline Age (years) & $51.4 \pm 16.3$ & $62.1 \pm 11.2$ & $<0.001$ & - \\
\hline $\mathrm{BMI}\left(\mathrm{kg} / \mathrm{m}^{2}\right)$ & $22.5 \pm 3.4$ & $25.1 \pm 3.8$ & $<0.001$ & $0.034 * *$ \\
\hline Exercise $>1 \mathrm{~h}$ per week & $2,283 \quad(41.8)$ & $331 \quad(52.5)$ & 0.001 & $0.042 * *$ \\
\hline Current drinking & $455 \quad(8.3)$ & $50 \quad(7.9)$ & 0.729 & -0.002 \\
\hline Current smoking & $302 \quad(5.5)$ & $37 \quad(5.9)$ & 0.726 & 0.004 \\
\hline Femoral neck BMD T-score & $-0.913 \pm 1.184$ & $-1.132 \pm 1.184$ & $<0.001$ & $-0.025^{*}$ \\
\hline $\begin{array}{l}\text { Serum alkaline phosphatase } \\
\text { (IU/L) }\end{array}$ & $69.9 \pm 23.7$ & $78.4 \pm 22.9$ & $<0.001$ & $0.126 * *$ \\
\hline Serum total calcium $(\mathrm{mmol} / \mathrm{L})$ & $2.385 \pm 0.090$ & $2.400 \pm 0.090$ & $<0.001$ & - \\
\hline $\begin{array}{l}\text { Serum albumin-corrected } \\
\text { calcium }(\mathrm{mmol} / \mathrm{L})\end{array}$ & $2.302 \pm 0.084$ & $2.321 \pm 0.091$ & $<0.001$ & - \\
\hline $\begin{array}{l}\text { Serum parathyroid hormone } \\
(\mathrm{pmol} / \mathrm{L})\end{array}$ & $3.828 \pm 1.613$ & $3.657 \pm 1.582$ & 0.012 & $-0.102 * *$ \\
\hline Serum phosphate $(\mathrm{mmol} / \mathrm{L})$ & $1.129 \pm 0.154$ & $1.117 \pm 0.158$ & 0.067 & $0.161 * *$ \\
\hline Serum albumin $(g / L)$ & $44.2 \pm 2.9$ & $44.0 \pm 3.1$ & 0.084 & $0.426 * *$ \\
\hline Season (Winter and Spring) & $2414 \quad(44.2)$ & $283 \quad(44.8)$ & 0.746 & $0.027 *$ \\
\hline
\end{tabular}

Continuous variables express as mean $\pm \mathrm{SD}$.

Categorical variables express as $\mathrm{n}(\%)$

^Adjusted for age and sex; **p-value $<0.01$; *p-value $<0.05$ 
Table 2. Association between serum calcium concentration and diabetes incidence.

\begin{tabular}{|c|c|c|c|c|c|c|c|c|}
\hline \multirow[b]{2}{*}{ Variables } & \multicolumn{2}{|c|}{ Crude model } & \multicolumn{2}{|c|}{ Model 1} & \multicolumn{2}{|c|}{ Model 2} & \multicolumn{2}{|c|}{ Model 3} \\
\hline & $\begin{array}{c}\text { Hazard ratio per } \\
\text { 1-SD increment } \\
(95 \% \mathrm{CI})\end{array}$ & P-value & $\begin{array}{c}\text { Hazard ratio per } \\
\text { 1-SD increment } \\
(95 \% \mathrm{CI})\end{array}$ & P-value & $\begin{array}{c}\text { Hazard ratio per } \\
\text { 1-SD increment } \\
(95 \% \mathrm{CI})\end{array}$ & P-value & $\begin{array}{c}\text { Hazard ratio per } \\
\text { 1-SD increment } \\
(95 \% \mathrm{CI})\end{array}$ & P-value \\
\hline $\begin{array}{c}\text { Total } \\
\text { calcium }\end{array}$ & $1.19(1.10-1.28)$ & $<0.001$ & $1.16(1.08-1.25)$ & $<0.001$ & $1.16(1.08-1.26)$ & $<0.001$ & $1.11(1.02-1.21)$ & 0.016 \\
\hline $\begin{array}{l}\text { Albumin- } \\
\text { corrected } \\
\text { calcium }\end{array}$ & $1.28(1.18-1.38)$ & $<0.001$ & $1.09(1.01-1.18)$ & 0.026 & $1.08(1.00-1.17)$ & 0.066 & $1.10(1.02-1.20)$ & 0.018 \\
\hline
\end{tabular}

Model 1: adjusted for age and sex.

Model 2: model 1 further adjusted for BMI, smoking status, drinking status, and physical activity.

Model 3: model 2 further adjusted for serum albumin, serum phosphate, parathyroid hormone, alkaline phosphatase, femoral neck BMD

T-score, and season. 
Table 3. Hazard ratio (HR) of incident diabetes by quartiles of serum calcium concentration.

\begin{tabular}{|c|c|c|c|c|c|c|c|c|c|}
\hline Variables & & Q1 & & Q2 & & Q3 & & Q4 & $\mathrm{P}_{\text {Trend }}$ \\
\hline \multirow{5}{*}{$\begin{array}{c}\text { Total } \\
\text { calcium }\end{array}$} & $\begin{array}{c}\text { Cutoff } \\
(\mathrm{mmol} / \mathrm{l})\end{array}$ & $<2.33$ & & 2.33 to 2.38 & & 9 to 2.44 & & $>2.44$ & \\
\hline & Crude & 1 & 1.18 & $(0.93-1.50)$ & 1.42 & $(1.12-1.79)$ & 1.53 & $(1.21-1.92)$ & $<0.001$ \\
\hline & Model 1 & 1 & 1.21 & $(0.96-1.54)$ & 1.45 & $(1.15-1.83)$ & 1.49 & $(1.18-1.87)$ & $<0.001$ \\
\hline & Model 2 & 1 & 1.22 & (0.96-1.55) & 1.47 & $(1.16-1.85)$ & 1.49 & $(1.18-1.87)$ & $<0.001$ \\
\hline & Model 3 & 1 & 1.17 & $(0.91-1.49)$ & 1.37 & $(1.07-1.74)$ & 1.32 & $(1.02-1.70)$ & 0.032 \\
\hline \multirow{5}{*}{$\begin{array}{l}\text { Albumin- } \\
\text { corrected } \\
\text { calcium }\end{array}$} & $\begin{array}{c}\text { Cutoff } \\
(\mathrm{mmol} / \mathrm{l})\end{array}$ & $<2.25$ & & 2.25 to 2.29 & & 0 to 2.35 & & $>2.35$ & \\
\hline & Crude & 1 & 1.04 & $(0.81-1.35)$ & 1.32 & $(1.05-1.67)$ & 1.86 & $(1.48-2.34)$ & $<0.001$ \\
\hline & Model 1 & 1 & 0.91 & $(0.71-1.17)$ & 1.05 & $(0.83-1.32)$ & 1.22 & $(0.96-1.53)$ & 0.028 \\
\hline & Model 2 & 1 & 0.93 & $(0.72-1.20)$ & 1.01 & $(0.79-1.27)$ & 1.17 & $(0.93-1.48)$ & 0.082 \\
\hline & Model 3 & 1 & 0.96 & $(0.75-1.24)$ & 1.04 & $(0.82-1.32)$ & 1.22 & $(0.96-1.55)$ & 0.046 \\
\hline
\end{tabular}

Data are presented as HR (95\% CI)

Model adjustments are the same as indicated in Table 2. 
Figure 1. Forest plots in meta-analysis.

a) Association between serum total calcium levels and diabetes risk.

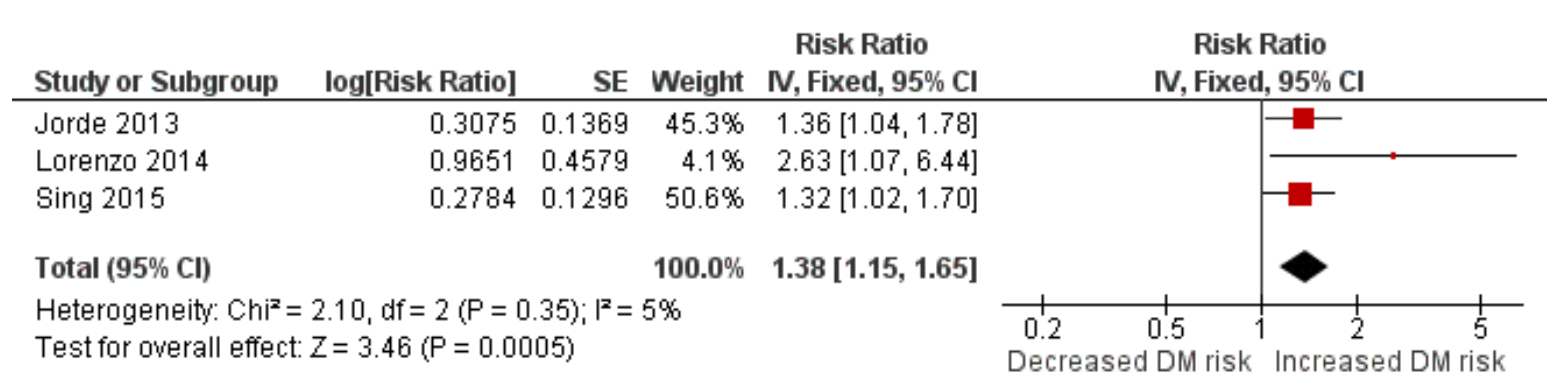

b) Association between albumin-corrected calcium levels and diabetes risk.

\begin{tabular}{|c|c|c|c|c|c|}
\hline Study or Subgroup & log[Risk Ratio] & SE & Weight & $\begin{array}{c}\text { Risk Ratio } \\
\text { IN, Fixed, } 95 \% \mathrm{Cl} \\
\end{array}$ & $\begin{array}{c}\text { Risk Ratio } \\
\text { IV, Fixed, } 95 \% \mathrm{Cl}\end{array}$ \\
\hline Becerra-Tomas 2014 & 0.5481 & 0.3686 & $9.4 \%$ & $1.73[0.84,3.56]$ & $\longrightarrow$ \\
\hline Lorenzo 2014 & 0.701 & 0.5184 & $4.8 \%$ & $2.02[0.73,5.57]$ & L \\
\hline Sing 2015 & 0.1978 & 0.1221 & $85.8 \%$ & $1.22[0.96,1.55]$ & \\
\hline Total $(95 \%$ Cl) & & & $100.0 \%$ & $1.29[1.03,1.61]$ & 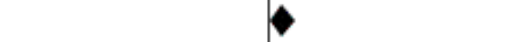 \\
\hline \multicolumn{5}{|c|}{$\begin{array}{l}\text { Heterogeneity: } \mathrm{Chi}^{2}=1.59, \mathrm{df}=2(\mathrm{P}=0.45) ; \mathrm{I}^{2}=0 \% \\
\text { Test for overall effect: } Z=2.25(\mathrm{P}=0.02)\end{array}$} & 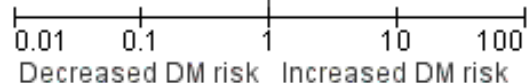 \\
\hline
\end{tabular}

